\section{Ciliary body position variability in glaucoma patients assessed by scleral transillumination}

P Agrawal and KR Martin

\begin{abstract}
Aim To quantify ciliary body position variability in glaucoma patients in order to determine if scleral transillumination should be used routinely to guide contact probe placement during cyclodestructive procedures. Method This was a prospective experimental study with human subjects. One hundred consecutive glaucoma patients attending a glaucoma clinic were recruited between June and November 2006. A fibre optic light source was used to identify ciliary body position by transscleral transillumination. The distance between the ciliary body and corneoscleral limbus was measured in the superior, temporal, inferior, and nasal quadrants of both eyes using surgical callipers.

Results The anterior boundary of the ciliary body was located $1.5-5 \mathrm{~mm}$ posterior to the corneoscleral limbus. The ciliary body was located significantly more posteriorly in the superior and inferior quadrants compared to the nasal and temporal quadrants. $(P<0.001)$. Ciliary body position was significantly correlated with the mean sphere of the refractive error in phakic patients $\left(r^{2}=0.052\right.$; $P=0.047)$. The ciliary body tended to be located most posteriorly in myopic eyes. Conclusions The distance between the corneoscleral limbus and the ciliary body as identified by transillumination varies significantly in different quadrants of the eye. Considerable variability was also observed between different patients with glaucoma. Ciliary body transillumination on patients undergoing cyclodestructive procedures may have implications for optimal probe placement and therapeutic outcome.
\end{abstract}

Eye (2008) 22, 1499-1503; doi:10.1038/eye.2008.79; published online 21 March 2008

Keywords: cyclodiode; ciliary body; glaucoma

\section{Introduction}

The pars plicata of the ciliary body is the site of aqueous production within the eye. In patients with refractory glaucoma, ablation of the ciliary processes using transscleral diode laser treatment delivered via a contact probe (cyclodiode) is a recognised therapeutic option to lower intraocular pressure. However, the optimal location for probe placement remains controversial. ${ }^{1,2}$ Previous light microscopy studies on a small number of human autopsy eyes have suggested optimal placement of the beam for the non-contact method to be $1.5 \mathrm{~mm}$ posterior to the corneoscleral limbus, ${ }^{3,4}$ and $0.5-1.0 \mathrm{~mm}$ for probe placement in contact cycloablation. ${ }^{5}$ However, the position of the ciliary body has been shown to be variable in different eyes and to vary with axial length. ${ }^{6}$

Thus, the optimal site for transscleral cycloablation may vary in different glaucoma patients. As an example, histological examination following 360-degree contact diode laser ablation $1.2 \mathrm{~mm}$ from the limbus revealed evidence of viable ciliary processes outside the treatment zone. ${ }^{7}$

Ultrasound biomicroscopy and transillumination can aid localisation of the ciliary body in individual patients and have been proposed as useful techniques to ensure that cyclodiode laser treatment is directed to the pars plicata. ${ }^{7-9}$ Ciliary body transillumination has been advocated in the context of congenital glaucoma, high myopia, and distortion of limbal anatomy secondary to previous surgery. ${ }^{10}$ However in otherwise normal eyes there is currently a lack of consensus on the necessity of localising the ciliary body before cycloablation.

To our knowledge the variability of ciliary body position in glaucoma patients has not been methodically investigated using transillumination techniques in a large case series. The purpose of this study was to
Department of Ophthalmology, Cambridge University Hospitals NHS Foundation Trust, Cambridge, UK

Correspondence: KR Martin Department of Ophthalmology, Eye Department Box 41 Cambridge University Hospitals NHS Foundation Trust,

Cambridge CB2 2QQ, UK

Tel: + 4401223 216427;

Fax: + 4401223 331174;

E-mail: krgm2@

cam.ac.uk

Received: 2 October 2007 Accepted in revised form: 19 February 2008 Published online: 21 March 2008

The authors have no relevant financial interest or competing interests in this paper. 
quantify this variability in a group of glaucoma patients to assess if transillumination should be performed on all patients before the delivery of cyclodiode laser treatment.

\section{Materials and methods}

\section{Patient selection and methods}

One hundred and five consecutive patients over the age of 18 years with a confirmed diagnosis of glaucoma (on the basis of confirmed optic disc and/or visual field changes) and on topical ocular hypotensive treatment were recruited from the glaucoma clinics at either Addenbrooke's Hospital, Cambridge or West Suffolk Hospital, Bury St Edmunds, United Kingdom between June and November 2006. Of these, 105 consecutive patients, 5 were excluded because of inability to comply with the examination.

After obtaining informed consent, a drop of proxymetacaine hydrochloride $0.5 \%$ preservative-free solution was instilled into each eye. It was noted whether the eye was phakic, pseudophakic, or aphakic. Other previous ocular pathology or surgery was also documented along with the patient's refractive error. The clinic room was darkened and a 495NL fibre optic light source (Karl Storz, Tuttlingen, Germany) was directed $4 \mathrm{~mm}$ posterior to corneoscleral limbus in each quadrant to identify the ciliary body by transscleral transillumination. The dark demarcation line was identified as the anterior margin of the ciliary body and surgical callipers were used to measure the distance between the visible corneoscleral limbus and the ciliary body (Figure 1). The corneoscleral limbus was identified as the clear boundary between the conjunctiva and cornea. All measurements were performed by one observer. Measurements were taken in the superior,

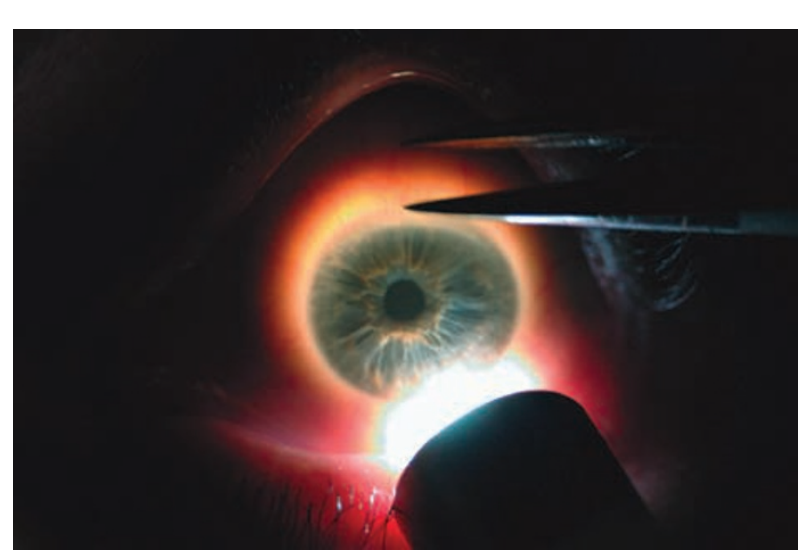

Figure 1 Transilluminated globe demonstrating the dark demarcation line. Callipers were used to measure the distance from the limbus. nasal, inferior, and temporal quadrant of each eye and recorded to the nearest $0.5 \mathrm{~mm}$. A separate cohort of 10 glaucoma patients underwent transscleral transillumination of their right eye as described by two independent observers to assess the strength of agreement between measurements.

It is our practice to transilluminate transsclerally to reduce the theoretical risk of retinal phototoxicity in eyes with advanced glaucoma, but transillumination is performed transcorneally in other centres. Therefore, to determine if the method of transillumination affected the interpretation of ciliary body position, a further 10 glaucoma patients underwent transscleral transillumination of the right eye in four quadrants using the method described above, as well as direct transillumination by shining the illuminating beam through the centre of the cornea.

All applicable institutional and governmental regulations concerning the ethical use of human volunteers were followed during this research.

\section{Statistical analysis}

Statistical analysis was performed using Graph Pad Prism 3.0 (GraphPad software Inc., San Diego, CA, USA). $P$-values of $<0.05$ were considered to indicate statistical significance. Data analysis were performed using a twotailed paired Student's $t$-test where data approximated to normal distribution and the Mann-Whitney $U$-test otherwise.

Where patients had bilateral glaucoma, one eye was randomly selected for inclusion in the analysis of variability between patients. Linear regression analysis was performed to assess the relationship between mean ciliary body position and mean sphere of the refractive error in phakic patients.

\section{Results}

A total of 180 glaucomatous eyes of 100 patients were evaluated. In all, 48 patients were female and 52 patients were male. Ninety-seven patients were Caucasian, three patients were Afro-Caribbean, and one patient was Asian. The mean age was $70.3 \pm 11.6$ years. Seventy-one patients $(73.9 \%, 133$ eyes) had primary open-angle glaucoma, 17 (16.7\%, 30 eyes) had normal tension glaucoma, 9 (6.7\%, 12 eyes) had secondary glaucoma, 2 $(1.7 \%, 3$ eyes) had chronic angle-closure glaucoma, and 1 $(1.1 \%, 2$ eyes) had aphakic glaucoma. One hundred and thirty-six eyes (75.6\%) were phakic, 40 (22.2\%) pseudophakic, and 4 (2.2\%) were aphakic. Seventeen patients had undergone previous glaucoma drainage surgery, three patients had undergone squint surgery, and another three patients previous retinal surgery. 
Table 1 Distance from limbus to anterior margin of the ciliary body as assessed by transscleral transillumination

\begin{tabular}{|c|c|c|c|c|c|c|c|c|}
\hline \multirow[t]{2}{*}{ Location } & \multicolumn{4}{|c|}{ Right eye $(\mathrm{n}=100)$} & \multicolumn{4}{|c|}{ Left eye $(\mathrm{n}=100)$} \\
\hline & Mean & $S D$ & Range & $95 \% C I$ & Mean & $S D$ & Range & $95 \% \mathrm{CI}$ \\
\hline Superior & 3.65 & 0.5 & $2.0-5.0$ & $3.55-3.74$ & 3.68 & 0.48 & $2.0-5.0$ & $3.58-3.77$ \\
\hline Nasal & 2.6 & 0.45 & $1.5-4.0$ & $2.51-2.68$ & 2.53 & 0.4 & $1.5-3.5$ & $2.45-2.61$ \\
\hline Inferior & 3.08 & 0.4 & $2.0-4.0$ & $3.0-3.16$ & 3.05 & 0.42 & $2.0-4.0$ & $2.97-3.13$ \\
\hline Temporal & 2.65 & 0.43 & $1.5-3.5$ & $2.56-2.73$ & 2.62 & 0.48 & $1.0-3.5$ & $2.53-2.72$ \\
\hline
\end{tabular}

CI, confidence interval; SD, standard deviation. All values are in $\mathrm{mm}$.

Table 2 Ciliary body position as identified using the transscleral and transcorneal methods of transillumination

\begin{tabular}{|c|c|c|c|c|c|c|c|c|}
\hline \multirow[t]{2}{*}{ Location } & \multicolumn{4}{|c|}{ Transscleral transillumination } & \multicolumn{4}{|c|}{ Central transillumination } \\
\hline & Mean & $S D$ & Range & $95 \% \mathrm{CI}$ & Mean & $S D$ & Range & $95 \% C I$ \\
\hline Superior & 2.85 & 0.47 & $2.5-3.5$ & $2.51-3.19$ & 2.55 & 0.37 & $2.0-3.0$ & $2.29-2.81$ \\
\hline Nasal & 2.6 & 0.7 & $2.0-4.0$ & $2.10-3.10$ & 2.3 & 0.4 & $2.0-3.0$ & $2.05-2.55$ \\
\hline Inferior & 2.7 & 0.54 & $2.0-3.5$ & $2.32-3.08$ & 2.45 & 0.37 & $2.0-3.0$ & 2.19-2.71 \\
\hline Temporal & 2.75 & 0.63 & $2.0-4.0$ & $2.30-3.20$ & 2.35 & 0.41 & $2.0-3.0$ & $2.06-2.64$ \\
\hline
\end{tabular}

CI, confidence interval; SD, standard deviation. All values are in $\mathrm{mm}$.

The spherical equivalent ranged from -2 to +4 .

Table 3 Comparison of ciliary body position in each quadrant between phakic and pseudophakic/aphakic eyes

\begin{tabular}{|c|c|c|c|c|c|c|c|c|}
\hline \multirow[t]{2}{*}{ Location } & \multicolumn{4}{|c|}{ Phakic eyes $(\mathrm{n}=76)$} & \multicolumn{4}{|c|}{ Pseudophakic/aphakic $(\mathrm{n}=24)$} \\
\hline & Mean & $S D$ & Range & $95 \% \mathrm{CI}$ & Mean & $S D$ & Range & $95 \% \mathrm{CI}$ \\
\hline Superior & 3.68 & 0.54 & $2.5-5.0$ & $3.55-3.80$ & 3.71 & 0.36 & $3.0-4.5$ & $3.56-3.86$ \\
\hline Nasal & 2.57 & 0.43 & $2.0-4.0$ & $2.47-2.67$ & 2.6 & 0.44 & $2.0-3.5$ & $2.42-2.79$ \\
\hline Inferior & 3.05 & 0.39 & $2.0-4.0$ & $2.96-3.14$ & 3.17 & 0.5 & $2.5-4.0$ & $2.95-3.38$ \\
\hline Temporal & 2.66 & 0.43 & $1.5-3.5$ & $2.57-2.76$ & 2.54 & 0.51 & $1.0-3.0$ & $2.33-2.76$ \\
\hline
\end{tabular}

$\mathrm{CI}$, confidence interval; SD, standard deviation. All values are in $\mathrm{mm}$ from limbus to anterior margin of ciliary body as assessed by transscleral transillumination. Total $n=100$ eyes of 100 glaucoma patients (for patients with bilateral glaucoma, one eye was selected randomly for inclusion in the analysis).

The mean position of the anterior border of the ciliary body was $2.98 \pm 0.36 \mathrm{~mm}$ from the limbus in the right eye compared to $2.96 \pm 0.36 \mathrm{~mm}$ in the left eye (Table 1). The ciliary body position in each quadrant of each eye was highly correlated ( $r=0.78$ superior quadrant; $r=0.77$ temporal quadrant; $r=0.80$ inferior quadrant; $r=0.68$ nasal quadrant). The ciliary body was located consistently more posteriorly in the superior and inferior quadrants than the nasal and temporal quadrants $(P<0.001)$, with the superior aspect of the ciliary body the most posterior. The mean position of the anterior border of the ciliary body was greater than $1 \mathrm{~mm}$ more posterior in the superior quadrant than in the nasal and temporal quadrants (Table 1). Variation in ciliary body position was slightly greater in the superior quadrant relative to the other quadrants and the range of values wider (2.0-5.0 mm). Measurements undertaken by the two independent observers showed $100 \%$ agreement of ciliary body position within $0.5 \mathrm{~mm}$ in the superior, inferior and nasal quadrants, and $80 \%$ agreement in the temporal quadrant. Comparison of ciliary body position in all four quadrants in a separate cohort of 10 glaucoma patients using both transscleral and transcorneal transillumination suggested that the transscleral approach may locate the ciliary body slightly more posteriorly (Table 2). However, the difference did not reach statistical significance in any individual quadrant $(P=0.18$ superior quadrant; $P=0.12$ temporal quadrant; $P=0.24$ inferior quadrant; $P=0.24$ nasal quadrant, Table 2 ).

There was no significant difference in ciliary body position in any individual quadrant between phakic and pseudophakic/aphakic eyes (Table 3). Statistical analysis of mean ciliary body position between phakic and pseudophakic/aphakic eyes also showed no significant difference ( $P=0.88$, Table 4$)$. The mean range of ciliary body position in individual phakic eyes was $1.18 \mathrm{~mm}$ $(\mathrm{SD}=0.47 \mathrm{~mm})$, compared to $1.29 \mathrm{~mm}(\mathrm{SD}=0.49 \mathrm{~mm})$ in pseudophakic/aphakic eyes. 
Table 4 Comparison of mean ciliary body position in phakic and pseudophakic/aphakic eyes

\begin{tabular}{lcccc}
\hline & Mean & $S D$ & Range & $95 \%$ CI \\
\hline $\begin{array}{l}\text { Phakic }(n=76) \\
\begin{array}{l}\text { Pseudophakic/aphakic } \\
(n=24)\end{array}\end{array}$ & 2.99 & 0.35 & $2.13-3.75$ & $2.91-3.07$ \\
\hline
\end{tabular}

$\mathrm{CI}$, confidence interval; SD, standard deviation. All values are in $\mathrm{mm}$ from limbus to anterior margin of ciliary body as assessed by transscleral transillumination.

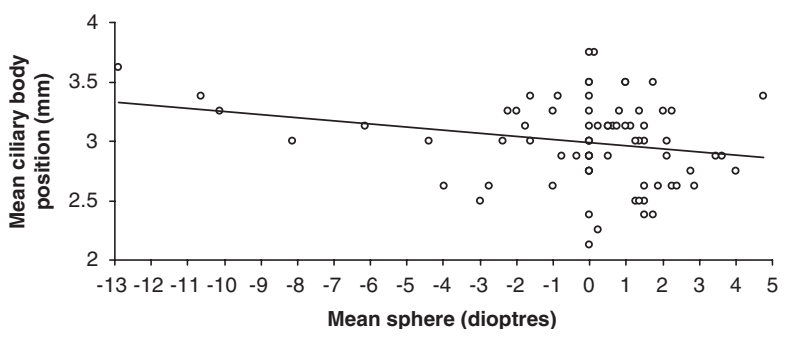

Figure 2 Linear regresson analysis, mean ciliary body position vs mean sphere.

The mean sphere of phakic eyes ranged from -12.88 to +4.75 dioptres. Linear regression analysis indicated a statistically significant correlation between mean ciliary body position in phakic eyes and mean sphere $\left(r^{2}=0.052\right.$; $P=0.047$, Figure 2). However, when the six eyes with greater than 4 dioptres of myopia were excluded from the analysis, the relationship between ciliary body position and mean sphere was not significant $\left(r^{2}=0.002\right.$; $P=0.70)$.

\section{Discussion}

Direct visualisation of the ciliary processes is not usually possible when cyclodestructive procedures are commonly performed by the transscleral approach. Thus, the ablative energy is directed toward an 'invisible' target unless indirect methods are used to determine ciliary body position. Ciliary body transillumination is used routinely by some ophthalmologists as a complementary tool for cyclodestructive procedures. It is thought to demarcate the pars plicata accurately and enhance probe placement. ${ }^{9,11}$ Others perform cyclodiode ablation using parameters similar to those evaluated in cadaver eyes, ${ }^{12,13}$ although most of these measurements were calculated on only a few autopsy eyes and therefore may not be representative of glaucoma patients in general.

Using transillumination, we have demonstrated that ciliary body position varies in different quadrants of individual eyes. We have shown that the superior ciliary body lies most posteriorly, with an anterior margin ranging from 2 to $5 \mathrm{~mm}$ from the limbus and a mean location $1 \mathrm{~mm}$ posterior to either horizontal quadrant. Both horizontal quadrants were located more anteriorly and equidistant from the limbus. This pattern concurs with a previous report where pars plicata position was assessed histologically. ${ }^{14}$ It therefore appears that cyclodiode laser treatment directed at a standard distance from the corneoscleral limbus may not be ideal. However, delivery of laser energy to areas of the ciliary body other than the ciliary processes may still have some effect on intraocular pressure. ${ }^{15}$

The anterior margin of the ciliary body as measured by transillumination in our study was more posterior than the pars plicata position measured histologically by Prost, who found the pars plicata to be situated approximately $1.7 \mathrm{~mm}$ posterior to the corneoscleral limbus superiorly, $1.4 \mathrm{~mm}$ inferiorly, $0.9 \mathrm{~mm}$ in the nasal quadrant, and $1.0 \mathrm{~mm}$ temporally. ${ }^{14}$ It is therefore possible that the pars plicata may lie slightly anterior to the ciliary body margin as identified by transillumination. This should be taken into account for cycloablative treatments, such as cyclodiode, commonly performed using the OcuLight SLx $810 \mathrm{~nm}$ diode laser together with the Iris G-probe (Iris Medical Instruments). Laser energy is transmitted through a 600-microndiameter quartz fibre protruding $0.7 \mathrm{~mm}$ from the G-probe contact surface, $1.2 \mathrm{~mm}$ from the limbus. ${ }^{16,17}$ The design of the G-probe ensures energy is delivered more posterior than the indent made by the fibre protrusion. ${ }^{18}$ Our results suggest that G-probe placement $1.2 \mathrm{~mm}$ from the corneoscleral limbus may be sufficient to ablate the ciliary body in the horizontal quadrants; however, it may need to be moved more posteriorly in the vertical quadrants to achieve a similar effect. The smaller treatment area with cyclodiode compared to cryotherapy suggests that exact probe placement is likely to be more critical.

Transillumination of the ciliary body has been recommended in buphthalmic eyes and other conditions associated with abnormal ocular size, as well as in eyes with pannus, arcus senilis, or previous surgery where exact localisation of the corneoscleral limbus is difficult. ${ }^{8,10}$ In our study, the good agreement of measurements in all four quadrants between the two observers suggests that the corneoscleral limbus was consistently identified.

We routinely perform transscleral transillumination to reduce the theoretical risk of retinal phototoxicity, although we are unaware of any clinical study demonstrating such phototoxicity in glaucoma patients. As other centres routinely perform transcorneal transillumination and as the angle of transillumination might affect the observed position of the ciliary body shadow, we measured ciliary body position by both methods in a further group of patients after the main 
study had been completed. We found no significant statistical difference in ciliary body position in each quadrant as identified by transscleral and transcorneal transillumination.

Our results demonstrated a significant correlation between mean ciliary body position and myopia. Although the strength of the correlation was weak, all six of the patients with more than 4 dioptres of myopia had a mean ciliary body position of greater than $3 \mathrm{~mm}$ from the limbus. When eyes with greater than 4 dioptres of myopia were removed from the regression analysis the relationship between mean ciliary body position and myopia was not significant. Transillumination may therefore be particularly useful in high myopes where the ciliary body may lie more posteriorly. We did not observe consistent differences in ciliary body position between different types of glaucoma, although the study was not large enough to exclude the possibility that such differences may exist.

From our results, we would predict that transillumination should improve the consistency of outcome in cyclodestructive procedures, but a randomized, controlled clinical study would be necessary to determine the effect of transillumination on treatment success.

In summary, we are aware of no previously reported study that has assessed ciliary body position variability using transillumination techniques in a large number of glaucoma patients. The results of our study indicate that ciliary body position relative to the limbus may vary markedly between different quadrants of the same eye and between different glaucoma patients. Ciliary body position also varies significantly with refractive error, although the correlation is relatively weak. Ciliary body transillumination on patients prior to cyclodiode laser treatment may therefore have implications for optimal probe placement and potentially therapeutic outcome.

\section{Acknowledgements}

This study was supported by Addenbrooke's Hospital Glaucoma Research Fund.

\section{References}

1 Kosoko O, Gaarsterland DE, Pollack IP, Enger CL. The Diode Laser Ciliary Ablation Study Group. Long-term outcome of initial ciliary ablation with contact diode laser transscleral cycophotocoagulation for severe glaucoma. Ophthalmology 1996; 103(8): 1294-1302.
2 Schubert HD. Cyclophotocoagulation: how far posterior to the limbus is the ciliary body. Ophthalmology 1989; 96(1): 139-140.

3 Marsh P, Wilson DJ, Samples JR, Morrison JC. A clinicopathologic correlative study of noncontact transscleral Nd: YAG cyclophotocoagulation. Am J Ophthalmol 1993; 115(5): 597-602.

4 Hampton C, Shields MB. Transscleral neodymium-YAG cyclophotocoagulation. A histologic study of human autopsy eyes. Arch Ophthalmol 1988; 106(8): 1121-1123.

5 Allingham RR, de Kater AW, Bellows R, Hsu J. Probe placement and power levels in contact transcleral neodymium: YAG cyclophotocoagulation. Arch Ophthalmol 1990; 108(5): 738-742.

6 Frieling E, Dembinsky B. Morphometry of the ciliary body using ultrasound biomicroscopy. Ophthalmologe 1995; 92(5): 745-749.

7 Walland MJ, McKelvie PA. Diode laser cyclophotocoagulation: histopathology in two cases of clinical failure. Ophthalmic Surg lasers 1998; 29(10): 852-856.

8 Brancato R, Carassa RG. Value of ultrasound biomicroscopy for ciliodestructive procedures. Curr Opin Ophthalmol 1996; 7(2): 87-92.

9 Sharkey JA, Murray TG. Identification of the ora serrata and ciliary body by transillumination in eyes undergoing transscleral fixation of posterior chamber intraocular lenses. Ophthalmic Surg 1994; 25(7): 479-480.

10 Vernon SA, Koppens JM, Menon GJ, Negi AK. Diode laser cycloablation in adult glaucoma: long-term results of a standard protocol and review of current literature. Clin Experiment Ophthalmol 2006; 34(5): 411-420.

11 Boniuk M. Cryotherapy in neovascular glaucoma. Trans Am Acad Ophthalmol Otolaryngol 1974; 78(2): 337-343.

12 Assia EI, Hennis HL, Stewart WC, Legler UF, Carlson AN. A comparison of neodymium: yttrium aluminium garnet and diode laser transscleral cyclophotocoagulation and cyclocryotherapy. Invest Ophthalmol Vis Sci 1991; 32(10): 2774-2778.

13 Hennis HL, Assia EI, Stewart WC, Legler UF, Apple DJ. Transscleral cyclophotocoagulation using a semiconductor diode laser in cadaver eyes. Ophthalmic Surg 1991; 22(5): 274-278.

14 Prost M. Anatomy of the ciliary body and cyclocryotherapy. Ophthalmologica 1984; 188(1): 9-13.

15 Liu GJ, Mizukawa A, Okisaka S. Mechanism of intraocular pressure decrease after transscleral continuous-wave $\mathrm{Nd}$ : YAG laser cyclophotocoagulation. Ophthalmic Res 1994; 26(2): 65-79.

16 Pastor SA, Singh K, Lee D, Juzych MS, Lin SC, Netland PA et al. Cyclophotocoagulation: a report by the American academy of ophthalmologists. Ophthalmology 2001; 108(11): 2130-2138.

17 Gupta N, Weinreb R. Diode laser cyclophotocoagulation. J Glaucoma 1997; 6(6): 426-429.

18 Gaasterland DE, Pollack IP. Initial experience with a new method of laser transscleral cyclophotocoagulation for ciliary ablation in severe glaucoma. Trans Am Ophthalmol Soc 1992; 90: 225-246. 